\section{Portal and splenic vein occlusion complicating Histoacryl injection therapy in bleeding gastric varices}

Endoscopic injection therapy with n-butyl-2-cyanoacrylate (NBCA) (Histoacryl ${ }^{\circledR}$, B. Braun, Melsungen, Germany) is an effective hemostatic treatment for gastric variceal bleeding [1]. In this report we describe a case of portal and splenic vein occlusion after injection therapy with NBCA.

A 48-year-old woman with liver cirrhosis was admitted with fundic variceal bleeding. Endoscopic injection therapy with NBCA was initiated and hemostasis was achieved. Following this treatment, the patient developed ascites and pleural effusion. A computed tomography (CT) scan showed massive ascites and an NBCA embolus in the portal vein ( $\bullet$ Fig. 1). The patient developed renal failure, metabolic acidosis, massive leucocytosis, and an ileus. Intestinal ischemia was suspected.

This clinical picture was compatible with an abdominal compartment syndrome. The femoral venous pressure, which can be regarded as a surrogate marker for intra-abdominal pressure, was high (30 mm Hg), supporting the diagnosis of abdominal compartment syndrome. Because of her poor condition and liver cirrhosis it was decided not to perform a laparotomy, and the patient died. Postmortem examination showed an NBCA embolus in both portal and splenic veins. The small bowel was necrotic. No NBCA emboli were found in the mesenteric arteries.

Injection treatment with NBCA in variceal bleeding is effective and relatively safe [1]. Several complications have been re-

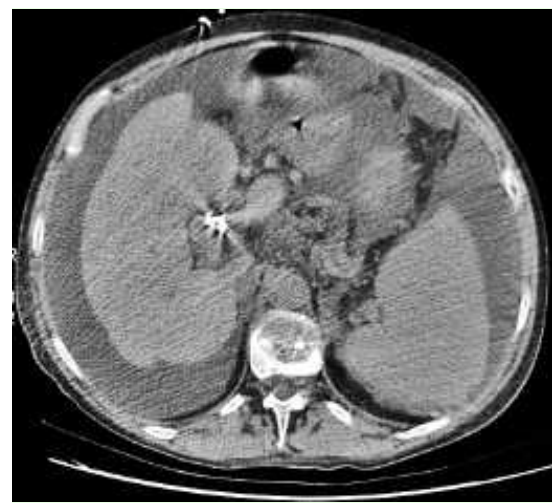

Fig. 1 Computed tomography scan showing n-butyl-2-cyanoacrylate embolus in the portal vein. No intravenous contrast was given because of compromised renal function.

ported, among which are pulmonary embolism [2], pericarditis [3], and intra-abdominal arterial embolization [4]. In our patient, the treatment of the bleeding fundic varices was complicated by portal and splenic vein embolization. To our knowledge, this complication has only been described once in the literature [5]. This resulted in tense ascites and pleural effusion, giving rise to an abdominal compartment syndrome. The intestinal ischemia can also be regarded as a result of this syndrome.

Portal vein occlusion following treatment with NBCA, although rare, should be considered in patients who develop massive ascites following this endoscopic intervention.

Endoscopy_UCTN_Code_CPL_1AH_2AC
W. J. Thijs ${ }^{1}$, E. H. de Groot ${ }^{2}$, L. S. Hofstra ${ }^{1}$

${ }^{1}$ Department of Internal Medicine and Gastroenterology, Scheper Ziekenhuis, Emmen, The Netherlands

2 Department of Radiology, Scheper Ziekenhuis, Emmen, The Netherlands

\section{References}

1 Huang $Y H$, Yeh HY, Chen GH et al. Endoscopic treatment of bleeding gastric varices by $\mathrm{N}$ butyl-2-cyanoacrylate (Histoacryl) injection: Long-term efficacy and safety. Gastrointest Endosc 2000; 52: 160-167

2 Alexander S, Korman MG, Sievert W. Cyanoacrylate in the treatment of gastric varices complicated by multiple pulmonary emboli. Intern Med J 2006; 36: 462 - 465

3 Chen YY, Shen TC, Soon MS, Lai JH. Lifethreatening pericarditis after N-butyl-2cyanoacrylate injection for esophageal variceal bleeding: Case report. Gastrointest Endosc 2005; 61: 487-489

4 Lee GH, Kim JH, Lee KJ et al. Life-threatening intraabdominal arterial embolisation after histoacryl injection for bleeding gastric ulcer. Endoscopy 2000; 32: 422-424

5 Shim CS, Cho YD, Kim JO et al. A case of portal and splenic vein thrombosis after Histoacryl injection therapy in gastric varices. Endoscopy 1996; 28: 461

\section{Bibliography}

DOI 10.1055/s-2007-966412

Endoscopy 2007; 39: 187

(c) Georg Thieme Verlag KG Stuttgart · New York . ISSN 0013-726X

\section{Corresponding author}

\section{W. J. Thijs, MD}

Department of Internal Medicine and

Gastroenterology

Scheperziekenhuis Emmen

Boermarkeweg 60

7824 AA, Emmen

The Netherlands

Fax: +31-591-691361

w.thijs@sze.nl 